\title{
CIDADÃO CONSCIENTE SE FAZ OUVIR
}

\section{Zélia Galvão Martiniano Lins ${ }^{1}$}

A regra de ouro da conduta é a tolerância mútua, porque nunca pensamos todos da mesma forma e sempre veremos só uma parte da verdade sob diferentes ângulos.

(GHANDI, 1998)

\section{Resumo}

Este artigo apresenta uma abordagem referente ao relacionamento entre os pacientes/usuários e a instituição pública de saúde com base nas experiências do atendimento durante os 20 anos na função de Ouvidor. Vale salientar que é muito gratificante o contato com as pessoas e poder contribuir para aliviar sua emoção, sua expectativa no universo hospitalar. Neste aspecto é importante se fazer ouvir. O que fariam essas pessoas sem ter quem os escutassem? A importância dessa prática e os benefícios que podem advir, em uma recíproca que nos coloca no lugar do outro. O paciente procura o hospital com problemas de saúde, doente, fragilizado pelo sofrimento, pela dor, ou mesmo que seu problema de saúde não the cause grandes males, mas tem algo que precisa ser analisado. É necessário que o processo de comunicação em uma Ouvidoria seja de mão dupla, ou seja, que aconteça entre o usuário que está buscando uma resposta e o servidor, bem como entre este e o profissional responsável pela área, com vistas a solucionar as questões levantadas.

Palavras-chave: Ouvidor. Práticas. Benefícios. Cidadão.

1 Formada em Serviço Social e Direito pela Universidade Católica de Pernambuco - UNICAP. Certificada no Curso Oficial de Ouvidoria Ombudsman pela Associação Brasileira de Ouvidores - Seccional Pernambuco. Funcionária Pública da Universidade de Pernambuco. Ouvidora Pioneira do Estado na Implantação da Primeira Ouvidoria de Saúde no Hospital Universitário Oswaldo Cruz em 1994. Atualmente Ouvidora do Pronto-Socorro Cardiológico Professor Luiz Tavares - PROCAPE. 


\begin{abstract}
This article presents an approach regarding the relationship between the patients / users and the public health institution based on the experiences of care during the 20 years in the function of Ombudsman. It is worth mentioning that it is very rewarding contact with people and contribute to ease your emotion, your expectation in the hospital environment. In this respect it is important to be heard. What would these people do with nobody listening to them? The importance of this practice and the benefits that can accrue on a reciprocal which puts us in the place of another. The patient looks for the hospital with health problems, sick, frail by suffering, by pain, or even if his health problem does not cause him great ills, but there is something that needs to be analyzed. It is necessary that the process of communication in an ombudsman's office be two-way, that is, that happens between the user who is seeking a response and the server, as well as between this and the professional responsible for the area, with a view to solving the issues raised.
\end{abstract}

Keywords: Ombudsman. Practices. Benefits. Citizen. 


\section{INTRODUÇÃO}

A Ouvidoria é uma atividade institucional de representação autônoma e independente que acoIhe as manifestações dos cidadãos não solucionadas por outros canais de atendimento, que analisa e atua na busca de soluções, identifica tendências para recomendar e orientar a organização, fomentando a promoção da melhoria contínua do trabalho e a busca de soluções efetivas.

O usuário, na instituição pública de saúde, diante da doença ou da ameaça dela, considerando que seu direito de cidadão não está sendo respeitado, procura a Ouvidoria para expor a dificuldade enfrentada.

De uma maneira geral, uma Ouvidoria hospitalar é procurada pelo usuário como uma medida urgente, com a mesma expectativa que se busca qualquer que seja o profissional, para a solução de um problema imediato.

No entanto, e lamentavelmente, as pessoas não têm condições de pagar um convênio e esperam, no serviço público de saúde, não apenas do médico, mas de tudo o mais, ou seja, de todo o pessoal e as equipes profissionais que compõem os serviços do hospital, que seu atendimento seja concluído satisfatoriamente.

Diante de sua expectativa não satisfeita, ao longo do caminho que percorreu dentro do hospital, o usuário recorre à Ouvidoria e espera dela uma resposta que o leve a resolver o problema. Naquele exato momento ele avalia criticamente a situação, tomado por uma emoção natural diante da situação, a forma como foi atendido, rotulando o seu ponto de vista, sua visão acerca do atendimento hospitalar ou do médico, analisando criteriosamente cada caso.

O paciente procura o hospital com problemas de saúde, doente, fragilizado pelo sofrimento, pela dor, ou mesmo que seu problema de saúde não lhe cause grandes males, mas tem algo que precisa ser analisado.

Ninguém vem ao médico por estar "alegre". Alguns são doentes do corpo e da alma e estão de mal com a vida. É uma questão cultural. A pessoa vem ao hospital procurar ser atendido e espera ser tratado.

Neste contexto, lutam, apelam, reagem e não aceitam a negação, porque sua vida está em jogo, seu maior bem. Assistência à saúde é um direito, não se admite limitações. A Política do Sistema de Saúde Pública não satisfaz. A negação do atendimento médico à população causa revolta.

O usuário de um Serviço Público de Saúde faz jus à prestação de um serviço de boa qualidade, de ser tratado com humanidade e respeito no atendimento, assim como:

- atendimento por ordem de chegada;

- prioridade ao idoso, grávidas e deficientes físicos;

- igualdade de tratamento, vedada a discriminação;

- racionalização na prestação de serviços mais eficientes;

- adequação entre meios e fins, não se admitindo imposição de exigência, obrigações, restrições e sanções, salvo o que determina a Constituição Federal;

- cumprimento de horário ao bom atendimento do usuário, prazos e normas procedimentais; 
- manutenção de instalações limpas, sinalizadas, acessíveis e adequadas aos serviços ou atendimentos;

- observação dos códigos de ética aplicáveis às várias categorias e agentes públicos.

A forma como será atendido é de vital importância, trazendo-lhe alegria e satisfação, apesar da doença. $O$ tratamento representa para o doente a cura da doença e a restituição da sua saúde.

\section{REFERENCIAL TEÓRICO}

No Brasil aconteceu a implantação de sistemas de Ouvidorias na área da saúde em âmbito institucional e governamental. Esses sistemas associam-se à crise e às transformações que se verificaram na área na década de 1990, visto que as circunstâncias se tornaram favoráveis ao surgimento de propostas que se voltassem para a participação e o controle do povo sobre as atividades de prestação de serviços de saúde. Tais propostas foram focadas a partir da Constituição de 1988 e da Lei do SUS, em 1990 (SOUZA, 2010).

A consolidação da Ouvidoria se relaciona diretamente à capacidade governamental de exercer democraticamente a gestão, através do controle e da participação popular para com as definições e a fiscalização da política de saúde.

De acordo com SILVA, PEDROSO e ZUCCHI (2014, p. 135), o desenvolvimento das Ouvidorias Públicas em saúde é instrumento de controle social e tem como função principal controlar o funcionamento da Administração Pública, denunciando eventuais falhas e difundindo os princípios de justiça entre os cidadãos. As Ouvidorias são caracterizadas "como instrumento de visibilidade do Estado, espaços democráticos de participação popular e ferramenta de gestão, pautadas nos princípios éticos e constitucionais da administração pública e do Sistema Único de Saúde".

Essencialmente, a Ouvidoria tem como característica fazer o aprimoramento da qualidade referente ao atendimento, objetivando a satisfação do cidadão, o que se confirma através dos significados de capital social e humanização que apontam para o cidadão. A atividade de comunicação, em suas variadas características e definições, demonstra sua primordial importância para as atividades da Ouvidoria, visto que ela constitui um espaço de democracia, onde existe a participação e a representação popular (IERVOLINO; ARMADA; MORAES, 2011).

É necessário que o processo de comunicação em uma Ouvidoria seja de mão dupla, ou seja, que aconteça entre o usuário que está buscando uma resposta e o servidor, bem como entre este e o profissional responsável pela área, com vistas a solucionar as questões levantadas. Segundo KUNSCH (2003, p. 82), essa rede é formal por ser um "conjunto de canais e meios de comunicação estabelecidos de forma consciente e deliberada".

Tal bilateralidade da Ouvidoria objetiva conduzir os interesses, as motivações, as intenções, os conflitos e os demais afetos (IASBECK, 2012).

Nesse vai e vem de informações, a própria gestão de saúde consegue se beneficiar delas através de relatórios repassados pela Ouvidoria, e esse processo pode demonstrar as falhas

110 | Revista Científica da Associação Brasileira de Ouvidores/Ombudsman - Ano 1 - n 1 - 2017/2018 
do sistema, oportunizando sua melhoria e resolvendo problemas desconhecidos por meio de soluções práticas e objetivas. Salienta-se que a Ouvidoria não é um setor criado para apontar erros alheiros, mas dá suporte no auxílio às melhorias da qualidade de serviços e produtos, ou seja, é um processo de constante aprimoramento no seio da organização, com vistas a que os resultados cheguem até os cidadãos e suas necessidades (VISMONA, 2011).

\section{PROCEDIMENTOS METODOLÓGICOS}

Foi utilizada para a formalização deste artigo uma metodologia descritiva. Buscou-se ouvir pacientes que utilizam o Hospital em estudo com o objetivo de encontrar as falhas no atendimento, bem como identificar os pontos a serem melhorados no que se refere à forma como estes pacientes são atendidos, bem como as consequências advindas dela. A seguir, relatos de alguns pacientes que participaram da pesquisa.

Para a metodologia foram pesquisados artigos publicados na internet, bem como livros que embasassem o assunto, além da experiência da autora em contato com os pacientes e usuários.

\subsection{Relatos dos Pacientes \\ Relato do paciente 1}

\section{Fala do paciente}

"Estou traumatizado com o tratamento no atendimento."

\section{Argumentação}

- Paciente vai a um dos serviços hospitalares para receber o resultado de um exame. Insatisfeito e mal informado, procura a Ouvidoria reclamando da funcionária que respondeu com indiferença: "Não está assinado", ou não deu a devida explicação nem atenção, baixou a cabeça e deixou o paciente descontente; este, por sua vez, procura a Ouvidoria.

- A Ouvidoria fala com a funcionária para compreender melhor o problema; ela justifica-se relatando que o paciente "é mais grosso que papel de embrulhar prego" e que informou que o médico viria assinar o exame à tarde. Observa-se assim que o conflito foi gerado.

\section{Ouvidoria}

Colocamos para o paciente a informação com o convencimento de que a funcionária já o havia orientado.

\section{Paciente}

Argumento do paciente, muito tranquilo.

"Agora estou recebendo a informação correta, a funcionária não sabe atender, ela não olhou pra mim, me tratou mal, não me deu ouvidos." 


\section{Ouvidoria}

Combinamos que retornasse depois de dois dias para dar tempo para o exame ser assinado e para que não perdesse a viagem até o hospital. O paciente saiu satisfeito e agradecido com a atenção que Ihe foi dedicada.

Este exemplo é frequente em muitos casos que chegam à Ouvidoria, embora às vezes não identifiquemos de quem é a razão, mesmo porque o importante é resolver o problema. A Ouvidoria não pode contribuir para criar ou acirrar conflitos, deve, antes, resolvê-los.

\section{Ações da Ouvidoria}

1. Humanizar o atendimento.

2. Escutar o paciente aflito, que vem à procura de uma explicação para sua dificuldade.

3. Analisar, esclarecer a dificuldade e intervir adequadamente, buscando assegurar uma assistência digna ao cidadão.

Caberá ao interessado requerer o que for de direito. A Ouvidoria aguarda a manifestação do(s) prejudicado(s) para eventual tomada de decisão junto aos gestores, que analisarão a relevância da reclamação. Os casos emergenciais são resolvidos de imediato.

\section{Relato do paciente 2}

\section{Fala do paciente}

"Não adiantou nada procurar este doutor, ele nem olhou para mim." "É muito grosso, pensei até que estava diante de um Delegado de Polícia."

\section{Argumentação}

- Necessitava um encaminhamento para o médico clínico, não estava se sentindo bem de saúde.

- O argumento do doutor negando-lhe atendimento foi "cruel" para o paciente.

- Resultado: o paciente nada conseguiu; o doutor culpou a dita Política do Sistema de Saúde que limitou o atendimento, além de atender às exigências do Serviço, que pretende limitar consultas.

- Pergunta-se: Futuramente os doutorandos quando concluírem o curso e passarem a exercer a Medicina em seu consultório particular vão escolher e discriminar pacientes? Será que estarão preparados para diagnosticar qualquer doença?

Análise: Sentimento de Onipotência do médico.

\section{Ouvidoria}

Qual o papel do Ouvidor neste caso?

1. Tranquilizar o paciente após ouvir sua história, dando apoio necessário.

2. Informar sobre a Instituição Hospitalar, explicando o porquê da negação. 
3. Analisar com o paciente sua queixa de saúde, a fim de tomar uma providência no sentido de conseguir o atendimento ou encaminhá-lo para outra Instituição de Saúde.

4. Convencer o paciente sem prejudicá-lo, bem como deixando claro que o Hospital poderá atendê-lo oportunamente.

\subsection{Visão da Realidade na Fala dos Pacientes}

Em muitos casos, na prática vivencial, o Ouvidor se depara com diversas situações em que tem o ofício de ouvir as argumentações, fazendo uma análise na busca da melhor solução para os casos. O quadro a seguir demonstra esse processo.

\begin{tabular}{|c|c|c|}
\hline FALA DO PACIENTE & SITUAÇÃO & ANÁLISE \\
\hline $\begin{array}{l}\text { "No céu, cachorro } \\
\text { morre latindo." }\end{array}$ & $\begin{array}{l}\text { Médico deixa o paciente } \\
\text { falando sozinho, dá as } \\
\text { costas para a família } \\
\text { do paciente. }\end{array}$ & $\begin{array}{l}\text { Avaliação existencial e } \\
\text { metafórica do ser humano, } \\
\text { pelo descaso médico. }\end{array}$ \\
\hline $\begin{array}{l}\text { "Abandonei o tratamento por } \\
\text { falta de atenção e de boa } \\
\text { vontade do médico, que } \\
\text { deixou o consultório sem } \\
\text { dar a menor atenção, me } \\
\text { deixando esperando para } \\
\text { consulta." }\end{array}$ & $\begin{array}{l}\text { Médico não atendeu, saiu } \\
\text { sem se justificar e sem } \\
\text { remarcar o atendimento. }\end{array}$ & $\begin{array}{l}\text { Desconsideração do médico } \\
\text { em relação à cidadania } \\
\text { e à dignidade do paciente. } \\
\text { Estrangulamento da relação } \\
\text { interpessoal. }\end{array}$ \\
\hline $\begin{array}{l}\text { "Considero a dificuldade do } \\
\text { atendimento médico, uma } \\
\text { sonegação dos direitos } \\
\text { humanos." }\end{array}$ & $\begin{array}{l}\text { A dificuldade } \\
\text { no atendimento. }\end{array}$ & $\begin{array}{l}\text { O paciente tem consciência } \\
\text { do seu direito aos serviços } \\
\text { da Saúde Pública e sente- } \\
\text { se lesado pelas dificuldades } \\
\text { encontradas como cidadão. } \\
\text { Ausência mínima de } \\
\text { compreensão do médico que } \\
\text { viola os direitos humanos. }\end{array}$ \\
\hline $\begin{array}{l}\text { "Se o paciente chega } \\
\text { atrasado ou fora da data } \\
\text { para receber medicação, } \\
\text { a médica diz está fazendo } \\
\text { um favor." }\end{array}$ & $\begin{array}{l}\text { As obrigações de trabalho } \\
\text { são transformadas em } \\
\text { favor ao paciente. }\end{array}$ & $\begin{array}{l}\text { Ausência de clareza das } \\
\text { obrigações profissionais, } \\
\text { rompimento de elos no } \\
\text { relacionamento interpessoal. }\end{array}$ \\
\hline $\begin{array}{l}\text { "Ouvi a médica dizer durante } \\
\text { a cirurgia que não sabia } \\
\text { operar com bisturi cego e } \\
\text { repetiu a mesma história } \\
\text { no consultório." }\end{array}$ & $\begin{array}{l}\text { Médico realiza cirurgia } \\
\text { com instrumento } \\
\text { defeituoso e } \\
\text { dá conhecimento } \\
\text { ao paciente. }\end{array}$ & $\begin{array}{l}\text { O paciente teme por sua } \\
\text { saúde, o médico expõe- } \\
\text { se e expõe o hospital a um } \\
\text { questionamento jurídico. }\end{array}$ \\
\hline $\begin{array}{l}\text { Médico revelou o } \\
\text { diagnóstico ao paciente e } \\
\text { informou a limitação } \\
\text { de seu tempo de vida. }\end{array}$ & $\begin{array}{l}\text { Os familiares não queriam } \\
\text { que o paciente soubesse } \\
\text { que tinha um tumor. }\end{array}$ & $\begin{array}{l}\text { Estímulo à pulsão de morte } \\
\text { (Tânatos). Mecanismo } \\
\text { de defesa da família pelo } \\
\text { estigma, negação da } \\
\text { doença, estigma da morte. }\end{array}$ \\
\hline
\end{tabular}




\begin{tabular}{|c|c|c|}
\hline FALA DO PACIENTE & SITUAÇÃO & ANÁLISE \\
\hline $\begin{array}{l}\text { "Quem quiser atendimento } \\
\text { melhor, que vá para o } \\
\text { sistema particular, pois o } \\
\text { sistema público funciona } \\
\text { desta maneira." }\end{array}$ & $\begin{array}{l}\text { Serviço público } \\
\text { com deficiência. }\end{array}$ & $\begin{array}{l}\text { Assumiu a responsabilidade } \\
\text { falsa e proclamada de que o } \\
\text { serviço público é ineficiente, } \\
\text { comprometendo com isso } \\
\text { desoladoramente todo o serviço } \\
\text { público. O paciente é obrigado } \\
\text { a aceitar as sugestões com } \\
\text { as quais se depara quando } \\
\text { em busca da saúde. }\end{array}$ \\
\hline $\begin{array}{l}\text { "Ninguém briga pelos } \\
\text { direitos sem ter certeza." }\end{array}$ & $\begin{array}{l}\text { Falta de } \\
\text { comunicação. }\end{array}$ & $\begin{array}{l}\text { A paciente tem conhecimento } \\
\text { de que saúde é um direito } \\
\text { e reivindica ajuda para } \\
\text { conseguir atendimento. }\end{array}$ \\
\hline $\begin{array}{l}\text { "Tem que mexer para } \\
\text { aprenderem a tratar bem o } \\
\text { ser humano, sou funcionário } \\
\text { público. Vim porque sei que } \\
\text { é hospital de referência. } \\
\text { Mesmo que não consiga } \\
\text { nada, fico satisfeito } \\
\text { em ser ouvido." }\end{array}$ & $\begin{array}{l}\text { Realização de } \\
\text { exame, médico } \\
\text { negou requisição. }\end{array}$ & $\begin{array}{l}\text { Falta de comunicação e } \\
\text { informação correta. O paciente } \\
\text { veio do IPSEP, com requisição. } \\
\text { Encaminhamos para o LACEN } \\
\text { - Secretaria de Saúde, onde } \\
\text { são feitos os exames de toda } \\
\text { a rede hospitalar. O paciente, } \\
\text { contrariado, não necessitava } \\
\text { aguardar das 7:00 às 11:00 para } \\
\text { chegar à Ouvidoria e receber } \\
\text { esta informação, tendo uma } \\
\text { injusta sobrecarga estressante. }\end{array}$ \\
\hline $\begin{array}{l}\text { "O velho idoso não } \\
\text { tem valor não, só } \\
\text { prestava no Brasil } \\
\text { Fidel Castro." }\end{array}$ & $\begin{array}{l}\text { Não conseguiu marcação } \\
\text { de consulta para a clínica } \\
\text { médica, mesmo com } \\
\text { encaminhamento. }\end{array}$ & $\begin{array}{l}\text { O idoso sentiu-se discriminado, } \\
\text { tem percepção de organização } \\
\text { e regime político e exige } \\
\text { seus direitos. Embora sua } \\
\text { simbologia política seja } \\
\text { altamente questionável. }\end{array}$ \\
\hline $\begin{array}{l}\text { "O médico pode chegar } \\
\text { atrasado, e a gente não } \\
\text { pode? Eu tenho os meus } \\
\text { direitos e estou atrás deles, } \\
\text { enfrentei a fila da marcação, } \\
\text { não vim pedir favor." }\end{array}$ & $\begin{array}{l}\text { Médico negou } \\
\text { atendimento. }\end{array}$ & $\begin{array}{l}\text { Negligência evidente } \\
\text { do paciente e necessária } \\
\text { pontualidade que confronta com } \\
\text { o exaustivo esforço burocrático } \\
\text { para chegar até o serviço para } \\
\text { o devido atendimento. }\end{array}$ \\
\hline $\begin{array}{l}\text { "Médico tomou os meus } \\
\text { exames das minhas mãos } \\
\text { e negou-se a devolvê-los, } \\
\text { dizendo que ninguém o } \\
\text { obrigaria a isso." }\end{array}$ & Exames errados. & $\begin{array}{l}\text { Paciente com consciência } \\
\text { de risco, motivado pela } \\
\text { falha do serviço. }\end{array}$ \\
\hline $\begin{array}{l}\text { "Médico desumano, } \\
\text { desatencioso e orgulhoso, } \\
\text { não ouve o paciente, pisa" } \\
\text { no chão para fazer favor." }\end{array}$ & $\begin{array}{l}\text { Forma como o médico } \\
\text { atendeu. }\end{array}$ & $\begin{array}{l}\text { O paciente percebe } \\
\text { desinteresse e má vontade } \\
\text { do médico que, aparentemente } \\
\text { julgando-se superior, faz } \\
\text { descaso da situação } \\
\text { do paciente. }\end{array}$ \\
\hline
\end{tabular}




\section{ANÁLISES}

A vantagem da Ouvidoria para o paciente é ter quem o escute pacientemente. Neste sentido, ressalta-se que a Ouvidoria é um instrumento de gestão que contribui com indicadores de desempenho para avaliar a satisfação das necessidades da população que procura atendimento.

A desvantagem da Ouvidoria é o desgaste do profissional. Os direitos existem para que cada cidadão tenha vida digna e decente.

Aprendemos com o sofrimento das pessoas. Realizar o serviço é bonito, gratificante, porém ingrato, tendo em vista que nem sempre resolve o problema, apenas o alivia. Em alguns casos, a verdade dos fatos narrados pelo paciente em sua reclamação à Ouvidoria passa a ser distorcida, o paciente foi a vítima e torna-se o responsável pelo problema. Mesmo com argumentos e diálogo, os profissionais apontados pelo paciente sempre têm razão.

Cria-se o impasse: onde está o problema? Na Política do Sistema de Saúde Pública ou nas pessoas? Ou o problema estará na estrutura que envolve as diversas categorias profissionais? Não se arreda o pé de uma posição para reconhecer e aceitar a falha do atendimento. E quando o paciente reclama, há uma negação injusta, punitiva, que prejudica todo o sistema do atendimento hospitalar, ocorrendo o conflito e o desgaste tanto para o paciente quanto para a Ouvidoria, porque ambos se sentem desacreditados.

A dedicação, a paciência, a tolerância são os segredos para quem quer ocupar o espaço de Ouvidor.

Entretanto, pode-se afirmar que tudo tem a ver com o ser humano, com as pessoas, com a personalidade, com o caráter, com a formação profissional. Na relação com as pessoas não se deve procurar culpados.

As pessoas são carentes de humanidade, querem ser tratadas com dignidade. É antiético discriminar o ser humano de qualquer forma ou sob qualquer pretexto, conforme consta do Código de Ética de todas as profissões e da Constituição Federal.

\section{RESULTADOS}

A Ouvidoria vem observando que o fluxo de queixas e reclamações diminuíram consideravelmente ao longo da implantação do serviço. Atendemos em média 50 casos/mês, comprovando que o número de insatisfação é pequeno em relação ao número de pacientes que diariamente procura atendimento no nosso Hospital. Essa mudança é um aspecto positivo, o ideal que continuaremos buscando.

Foram implantadas muitas mudanças decorrentes da criação da Ouvidoria. Em face desta experiência, o atendimento de saúde passou a ter mais qualidade. Apesar das solicitações que chegam de maneira geral, ainda existe resistência a mudanças.

A iniciativa da Ouvidoria tem por objetivo despertar a consciência dos que trabalham com doentes, atender aos seus anseios, vivenciando uma medicina humanizada, voltada para a pessoa em sua integridade psicossocial, respeitando os direitos humanos e garantindo a cidadania. Pautando-se 
na legalidade técnico-científica do tratamento aos pacientes, na transparência, na eficiência e prática dos valores democráticos, voltados para o aperfeiçoamento do ser humano e da Instituição.

As reclamações, atualmente, são exceções, pois o nível de satisfação dos pacientes é mais expressivo, afirmação feita com base nos elogios aos médicos em geral. Os pacientes quando procuram a Ouvidoria identificam perfeitamente os profissionais que os tratam com respeito, atenção e dignidade. A crítica é facilmente suportável pelos profissionais, desde que seu caráter esteja fora da causa.

A Ouvidoria age como pacificadora, a fim de manter um equilíbrio, uma mistura de severidade, de justiça, de dignidade e de afeição ao trabalho e à Instituição, como forma de remediar para evitar conflitos e queixas. As reclamações são cadastradas, o usuário tem direito de receber informações corretas para um bom funcionamento do Serviço Público. É necessário criar canais de comunicação dentro do Hospital que viabilizem a informação correta.

\section{CONSIDERAÇÕES FINAIS}

Com a implantação do sistema de software da Rede de Ouvidores, as manifestações são registradas no sistema na internet, possibilitando uma troca dinâmica e continuada da realidade. $\mathrm{O}$ trabalho do Ouvidor foi dinamizado, proporcionando, dessa forma, amplo intercâmbio e monitoramento dessas manifestações com novas expectativas.

Os Ouvidores de Pernambuco têm contribuído com notável sensibilidade e habilidade para aproximar o cidadão da Administração Pública com qualidade, objetivando a realização do direito como instrumento de justiça e cidadania.

Na solução dos casos, o Ouvidor desempenha um papel especialmente importante em colaboração com a instituição, contribuindo com o seu esforço e o seu trabalho em benefício da instituição do bem-estar, do bem comum. Assim como, ao corrigir pequenas falhas humanas, o Ouvidor orienta na solução dos desentendimentos gerados entre todas as partes envolvidas, processando os acordos que se conciliam imediatamente, sem causar prejuízos ao hospital, ao paciente ou aos profissionais da saúde. Dessa forma, resolve-se convenientemente o problema dentro da realidade social para o bem do próprio reclamante.

\section{REFERÊNCIAS}

IASBECK, Luiz Carlos Assis. Competências comunicacionais em Ouvidoria. In: IASBECK, Luiz Carlos Assis (Org.). Ouvidoria: mídia organizacional. Porto Alegre: Sulina, 2012.

IERVOLINO, Antonio; ARMADA, Rosandra; MORAES, Sidéia. Ouvidorias na área de saúde pública: reflexões sobre a prática. In: PEREZ, José; BARREIRO, Adriana; PASSONE, Eric (Org.). Construindo a Ouvidoria no Brasil: avanços e perspectivas. Campinas: Unicamp/ Ouvidoria, 2011.

KUNSCH, Margarida M. Krohling. Planejamento de relações públicas na comunicação integrada. 4. ed. rev., atual. e ampl. São Paulo: Summus, 2003.

SILVA, Rita de Cássia Costa da; PEDROSO, Marcelo Caldeira; ZUCCHI, Paola. Ouvidorias Públicas de saúde: estudo de caso em Ouvidoria Municipal de saúde. Revista de Saúde Pública, v. 48, n. 1, p. 134-141, 2014.

SOUZA, Raquel Costa Rodrigues de. A Ouvidoria como instrumento de avaliação e melhoria da qualidade dos cuidados de enfermagem. Dissertação de Mestrado. 96 p. Rio de Janeiro: Universidade Federal do Estado do Rio de Janeiro, 2010.

VISMONA, Edson. A evolução das Ouvidorias no Brasil. In: PEREZ, José; BARREIRO, Adriana; PASSONE, Eric (Org.). Construindo a Ouvidoria no Brasil: avanços e perspectivas. Campinas: Unicamp/ Ouvidoria, 2011. 